\title{
Exploring the Promotion and Inheritance of Traditional Culture in Primary Chinese Teaching
}

\author{
Jing Li \\ Teacher's college of Xi'an University, Xi'an, Shaanxi 710065
}

Keywords: Chinese teaching in Primary shools; Traditional clture; Promotion and iheritance

\begin{abstract}
The traditional culture of the Chinese nation is the result of the wisdom and experience of the ancient saints and working people in our country for 5,000 years. It is the foundation for the Chinese nation to survive and the spiritual pillar for the sustainable development of the Chinese nation. Carrying forward and inheriting the Chinese traditional culture is the responsibility and obligation of every Chinese citizen. At present, with the rapid economic development and the emergence of a new type of cultural media, various kinds of junk culture have exerted tremendous impact on the traditional Chinese culture. Their status has also been weakened. Teaching Chinese as an important means to carry forward the traditional Chinese culture, the elementary school stage is an important enlightenment period for the formation of students' ideological consciousness. Therefore, it is of great significance to promote traditional culture in primary Chinese teaching. On the premise of fully recognizing that traditional culture infiltrates the important meaning of Chinese teaching in primary schools, this article combs the current situation of carrying forward the traditional culture in primary Chinese teaching and puts forward some measures to promote and inherit excellent traditional culture in primary Chinese teaching, so as to achieve the practical effect of cultivating students' patriotic feelings and traditional cultural accomplishments and contributing to the promotion of traditional culture.
\end{abstract}

\section{Introduction}

In the history of human culture, no country has such a rich cultural heritage as China. Chinese culture has a long history. In recent years, both at the national level and academia, Chinese is actively exploring how to promote Chinese traditional culture. With the continuous deepening of the curriculum reform, the new curriculum standard for compulsory education (2011 edition) proposes that primary Chinese courses should recognize and absorb the profound wisdom of Chinese culture, care for contemporary cultural life, respect diverse cultures. Besides, Chinese teaching in primary school should carry forward the traditional culture. Chinese language and literature is not only a means of learning a language, but it is also the most important cultural learning tool. Carrying forward traditional culture should start from an early age so that students can form a specific awareness of traditional culture earlier. Primary language teachers should fully recognize the importance of primary language teaching, which shoulder the historic mission of cultural heritage. It is of great practical significance to cultivate the correct outlook on life and values for primary school students by penetrating our traditional culture in elementary school Chinese teaching and cultivating the primary school students' cultural qualities in the silent morals. At the same time, it has great practical significance for the inheritance of Chinese culture and the great rejuvenation of the Chinese nation.

\section{The Role of Primary Chinese Teaching in Promoting Traditional Culture}

Traditional culture, as an important component of the development of the Chinese nation, is closely linked with the progress of mankind and the development of society, and has a far-reaching impact on the healthy growth of young people. However, primary school students, as the most important group of people who inherit and carry forward outstanding traditional culture, are the foundation for the prosperity of ethnic culture. Therefore, primary school Chinese teaching must permeate traditional culture. In fact, many textbooks related to historical figures, myths and legends and 
customs in the primary Chinese teaching materials can all become the best carriers to penetrate the traditional culture. Primary Chinese teachers should consciously disseminate traditional culture in primary Chinese teaching, cultivate pupils' national awareness and patriotic awareness, and enable students to establish the sense of family-oriented in their efforts to promote Chinese traditional culture when they grow up.

\section{Current Situation of Traditional Culture Infiltration in Chinese Teaching in Primary Schools}

In our life, the shadow of excellent traditional culture can be seen everywhere, such as ceramics, Peking Opera, paper-cutting, and the unique festivals of our country. In the primary school language teaching materials, the shadow of traditional culture is also everywhere, such as classics, poetry and songs, myths and legends, folk tales, customs, festivals and ancient architecture. However, the specific penetration of teaching traditional culture is very limited. In the current primary school Chinese teaching, the parts related to traditional culture tend to be only ancient poems and classical Chinese teaching. Pupils can memorize these simple verses and simply understand them. Although these contents can initially understand our traditional culture, they lack an in-depth analysis of traditional culture. For example, most primary school language teachers teach the ancient poetry only briefly about the basic information of the dynasties and poets in which the poet was located. Other in-depth cultural connotations are rarely introduced. In this teaching mode, primary school students as a whole lack of understanding of Chinese traditional culture. In primary school Chinese teaching, primary language teachers mainly teach their tasks, emphasize the teaching of Chinese basic knowledge, blindly pursue scores and ignore to teach traditional culture. Primary school students are curious about new things. Primary school language teachers should try their best to attract primary school students' attention in the traditional culture teaching as much as possible, and abandon the monotonous and boring teaching methods of examination-oriented education, trying to make students learn in understanding.

\section{Measures of Developing and Inheriting Traditional Culture in Primary Chinese Teaching}

In view of the current situation of carrying forward and inheriting traditional culture in Chinese primary school teaching, we must make innovations in time. Correctly understand the status of traditional culture, attach importance to the penetration of traditional culture in primary Chinese teaching, and realize the intrinsic value of traditional culture. The specific practices are the following.

Improve Traditional Culture Accomplishment of Primary School Teachers. To enable pupils to become the backbone of inheriting and promoting traditional culture, teachers must first have a high level of traditional cultural accomplishment in primary school and enrich the content and form of teaching in their teaching. At present, in the reform and innovation education and teaching methods, many teachers have done a bold attempt and achieved good results. However, it is easy for many teachers to ignore the improvement of their own traditional culture accomplishment. For pupils, they do not yet have an independent learning ability, and their source of knowledge is mainly their teachers. This requires that teachers should constantly improve their own cultural literacy, continue to learn in teaching and exploration, in-depth understanding of the broad and profound Chinese culture. The teacher should always maintain his admiration for traditional culture, teach in words and deeds, influence students in a subtle way, and make the Chinese classroom an effective platform for spreading the traditional culture of the Chinese nation.

Permeate Traditional Culture in the Teaching of Ancient Poetry. As an important part of Chinese traditional culture, ancient poetry is also a major teaching point in current Chinese teaching of primary schools. Teaching in simple recitation and explanation, it is impossible to carry forward and heritage of traditional cultural goals. In order to achieve the best effect of infiltrating traditional culture in the teaching of limited ancient poems, students should feel as much as possible of the profound heritage of traditional culture. The infiltration of traditional culture in the teaching of ancient poetry can start from the content of the article and the emotional experience, and make use 
of the cultural concept of the poet's age to help students feel the traditional culture. Specific practices include as following. First, create a teaching situation. Traditional culture, as a more complex part of language learning, is often difficult for pupils to understand when teaching ancient poetry. In this regard, the language teachers should make full use of multimedia resources, through the video, pictures, etc. intuitively presented the traditional culture of author's time to deepen students' perception of traditional culture. Second, focus on the reference to other poems. If a teacher can introduce Wang Anshi's other ancient poems related to the theme of this ancient poem when teaches the fifth-grade poem "Boating at Gua Island", primary school students can contact with a wider range of ancient poems, which are better nurtured. Third, primary language teachers should pay attention to the expression of emotion in their teaching. In teaching, teachers should guide students to conduct rhythmical reading of ancient poems, enhance students' sense of language and experience poet's emotion in the process, so that students can deepen their understanding of traditional culture. Besides, teachers can also hold reading class in the classroom to stimulate students' interest in learning. Fourth, finish the infiltration of traditional culture through ethnic customs. During Wang Anshi's "Yuan Day" teaching, the teacher can broadcast the video of the traditional Spring Festival to the students so that they can understand the culture of the traditional Chinese festival. Students are then organized to further understand the rich connotation and form of traditional culture by attaching pairs of couplets and riddles. Finally, students can collect their own stories about the Spring Festival to stimulate interest in learning traditional culture. In addition, there are many ancient poems related to the Mid-Autumn Festival, the Dragon Boat Festival, the Chung Yeung Festival, and so on. During the teaching, ethnic customs can also be used to stimulate students' interest in learning.

Permeate Traditional Culture in Literacy Teaching. The penetration of traditional culture in Chinese teaching in primary schools can start from many aspects and should not be confined to the teaching scope of ancient classical Chinese and ancient poetry. It can also carry out cultural infiltration in literacy teaching. As a product of culture, Chinese teaching can not only infiltrate the traditional culture, but also help pupils to learn the important and difficult points of Chinese in primary school. Primary school students need to learn a lot of new words and the teaching of literacy is more boring, requiring teachers to adopt flexible teaching methods. First, teachers should explain the origin of "word" in the classroom when explaining the strokes of a specific word, from shallow to deep to get the purpose of infiltrating traditional culture. Second, introduce cultural codes to literacy teaching. For example, when teaching "Si", teachers can introduce "Si Maguang" who was a politician and historian in the Northern Song Dynasty in his teaching. Besides, teachers can also introduce Si Maguang's calmness and courage in facing difficult situations. This will help pupils to learn easily and deepen the pupils' understanding of the historical figure Si Maguang and embrace the traditional culture. Third, in the teaching of literacy, the traditional culture is infiltrated through the principles of word making in explaining the word. In explaining the word "love", the teacher can tell students that the traditional "love" is composed of three parts: "claw" and bald head, "heart" and "friend". The three parts together mean to seize the hearts of those who are like oneself.

Permeate Traditional Culture in Reading Teaching. The integration of traditional culture into primary school Chinese reading teaching can improve the traditional cultural accomplishment of primary school students and effectively play the role of educating people in Chinese teaching. In the fifth grade of elementary school, there is a lesson entitled "Grass Boat Borrowing Arrows". In this lesson, it talks about such figures as Zhu Geliang and Zhou Yu. In order to make pupils more deeply appreciate the personalities of these historical figures, teachers can introduce "Three Kingdoms" into the teaching and explain the basic situation to students. Then recommend students to read some easy to understand chapters, such as Zhu Geliang's "empty city". And then set the teaching task that what are the feelings of Zhuge Liang's approach and what kinds of excellent quality need students to learn. In later life, once involved in a similar scene, primary school students will naturally think of Zhu Geliang. When teaching the ancient myths such as "Jingwei Reclamation", teachers can start from the sacrificial spirit of ancient mythological figures. Zhaozhou Bridge and other traditional architecture text reading can help students understand our traditional architectural features. Through 
these teachers not only cultivate the reading ability of primary school students, but also open up the perspectives of primary school students. In the process of reading, teachers can also understand the historical figures, the traditional culture in historical buildings and enhance the patriotic feelings. In addition to class teaching, primary language teachers should also guide students to read more books related to traditional culture in extracurricular reading to let students feel the profound Chinese culture, appreciate the inherent charm of Chinese culture, and make contributions to the promotion and inheritance of traditional culture.

Permeate Traditional Culture in Writing Teaching. Teachers should guide students to accumulate material when cultivate pupils' writing ability at primary stage, which will help students to use material flexibly in writing. Therefore, teachers can introduce the related traditional culture into writing teaching. For example, when primary school students write about the composition of Spring Festival and Mid-Autumn Festival, teachers can introduce the origin of the Spring Festival and Mid-Autumn Festival to students. Then tell some stories behind and sum up some poems related to these festivals, which will increase primary school students' writing material and improve their writing ability.

\section{Conclusion}

To sum up, the penetration of traditional culture in primary Chinese teaching can enable pupils to learn and practice traditional culture from an early age, which is conducive to the flourishing of the traditional Chinese culture. Therefore, primary language teachers should actively explore how to penetrate traditional culture in all aspects of primary school language teaching according to the specific circumstances of primary school students, and then enhance the traditional culture of primary school students through subtle influences. Finally, students will accept traditional culture, promote and pass on traditional culture.

\section{Reference}

[1] People's Republic of China Ministry of Education. Compulsory Education Chinese Curriculum Standards. [S] Beijing: Beijing Normal University Press. 2011, (1)

[2] F. Y. He. How to Inherit Traditional Culture in Chinese Classroom Teaching [J]. Educational Modernization, 2017, (46): 204-205.

[3] R. W. Cai. Let Traditional Culture Shine in Primary School Chinese Teaching [J]. Education and Teaching Forum, 2016, (17): 253-254.

[4] X. B. Sun. Penetration of Traditional Culture in Primary Chinese Teaching [J]. China Out-of-School Education, 2015, (08): 45.

[5] W. Z. Hu. Introduction to Intercultural Communication [M]. Beijing: Foreign Language Teaching and Research Press, 1999.

[6] S. H. Cui. Culture Infiltration in Teaching Chinese as A Foreign Language [J]. Heilongjiang Higher Education Research, 2004, (3).

[7] W. Chen. Discussion of Cultural Problems in Teaching Chinese as A Foreign Language [J]. Modern Languages, 2006, (2).

[8] L. P. Gao. Cultural Consciousness in Teaching Chinese as A Foreign Language [J]. Nanjing Social Sciences, 2002, (2).

[9] F. Dong. Let Traditional Culture Bloom in Primary School Chinese Classroom [J]. Education and Teaching Forum, 2014, (21): 2-2.

[10]C. H. Bai. The Infiltration of Traditional Culture into Primary School Chinese Grammar Teaching [J]. Culture and Education, 2015, (16): 177-178.

[11]L. L. Zhang. Exploration of Permeating Traditional Culture in Teaching Chinese in Primary School [J]. Times Education, 2015, (20): 261-261. 